\title{
Variability and climate sensitivity of fast ice extent in the north-eastern Kara Sea
}

\author{
Dmitry Divine, Reinert Korsnes \& Alexander Makshtas
}

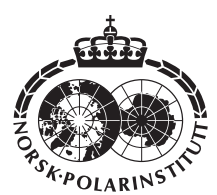

This work investigates the temporal and spatial variation of shore-fast ice extent in the north-eastern part of the Kara Sea during 1953-1990 and its sensitivity to interannual variability of the regional climate. The area of fast ice in spring months shows a bimodal distribution. This indicates the existence of two different regimes of fast ice formation driven by the system of prevailing winds. The westward wind transport during the cold season gives larger fast ice extent while the eastward wind transport suppresses the expansion of fast ice. There is a significant correlation (ca. -0.55 ) between the average winter temperature and the area of fast ice. Linear trends for time records of shore-fast ice area in spring show a decrease during 1953-1990. This decrease is most pronounced in April: the mean fast ice area in April is 12\% lower in 1988-1990 compared to 1953-55. A comparison of fast ice regimes for two particular years1979 and 1985-revealed a significant influence of cyclone activity on fast ice development over the course of the cold season. It is shown that partial break-ups of fast ice in spring 1985 are associated with the passage of cyclones across the area of fast ice.

D. V. Divine, Norwegian Polar Institute, Polar Environmental Centre, N-9296 Tromso, Norway, divine@, npolar.no; R. Korsnes, Norwegian Defense Research Establishment, Box 25, N-2007 Kjeller, Norway; A. P. Makshtas, International Arctic Research Center, 930 Koyukuk Drive, Box 757340, Fairbanks, AK 99775, USA.

The winter ice regime of the Kara Sea is characterized by the formation of large zones of stationary ice. Fast ice usually starts to form near the shoreline at the end of October to the beginning of November and expands seaward during December-February. It tends to reach its stable maximum in April-May. By this time the fast ice edge typically attains $10 \mathrm{~m}$ depth in the western part of the Kara Sea. In the eastern Kara Sea it can reach depths of about 20-30 $\mathrm{m}$ and even $100 \mathrm{~m}$ near the Severnaya Zemlya archipelago. The most extensive stretch of fast ice is observed in the north-eastern Kara Sea, where numerous islands and shallow banks prevent the ice from moving; fast ice extent in this area can attain hundreds of kilometres (Zubov 1945; Timokhov 1994; Borodachev 1998).

In years when the extent of fast ice has been especially large, the boundary of fast ice in the north-eastern Kara Sea extends from the tip of the Yamal Peninsula to the northern end of Severna Zemlya. In years when the observed fast ice extent has been particularly small, its border hugs the mainland (Fig. 1).

The investigation of shore-fast ice is important from several points of view. The presence of fast ice restricts offshore exploration and affects navigation. Variation of the extent of fast ice may indicate climate change both locally and on a global scale. The recurrent polynya bordering fast ice is the area where intensive heat exchange between the relatively warm water exposed to cold air occurs, resulting in the intensive formation of new ice and dense water (Dethleff et al. 1998). It is also believed that regions of fast ice and quasi-stationary polynyas are significant for 


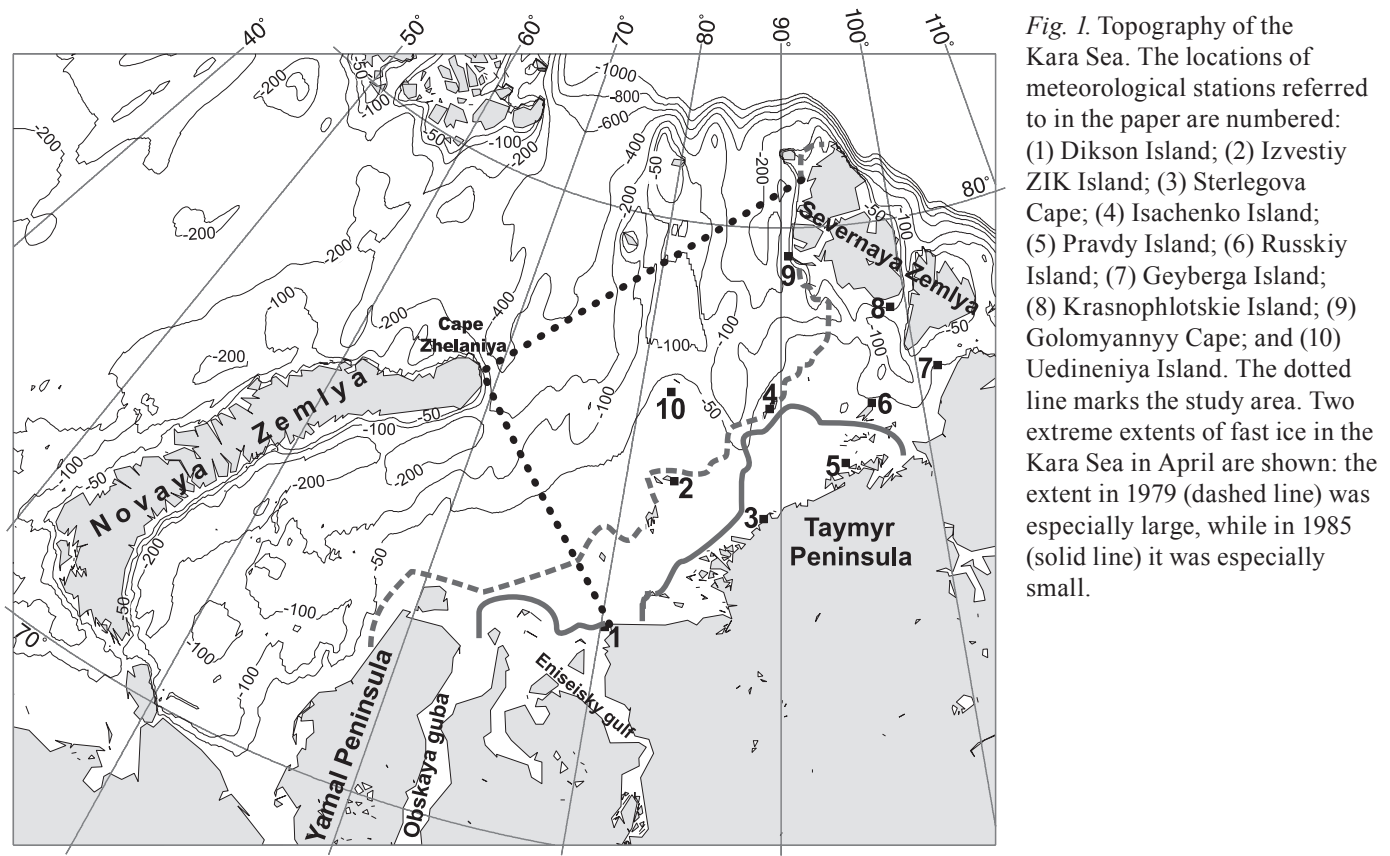

uptake of particulate materials and contaminants into sea ice from seawater (Reimnitz et al. 1992; Eicken et al. 1995; Reimnitz et al. 1995). These materials tend to melt out of the ice in the Greenland and Barents seas.

Here we investigate the temporal and spatial variation of shore-fast ice extent in the northeastern Kara Sea during 1953-1990 and its sensitivity to annual and interannual variation in climatic conditions in the study area. The years 1979 and 1985, which showed opposite scenarios of shore-fast ice development over the course of the cold season, are considered in detail.

The area under study is in the north-eastern Kara Sea, east of the "line" between Dikson Island and Zhelaniya Cape (the northern tip of Novaya Zemlya), and south of the "line" connecting the Zhelaniya Cape and the northern extremity of the Severnaya Zemlya archipelago (Fig. 1).

\section{Data sets}

Regular observations by the Arctic and Antarctic Research Institute (AARI), in St. Petersburg, during 1953-1990 provide data on fast ice extent (Fetterer \& Troisi 1997). The data set is mainly based on gridded ice reconnaissance charts derived from observations from aircraft, and visi- ble and infrared satellite imagery. The data's spatial resolution (pixel size) is $12.5 \mathrm{~km}$. The temporal data coverage is one survey a month during April to September 1953-1966. Since 1966 the number of surveys has been three per month in the period of navigation from June to September. In 1980-1990 there were three observations each month, year-round. Each survey is attributed to one of three 10-day periods of the month when the survey was made. The total number of surveys exceeds 500. When locating the fast ice border, the data precision lies within one pixel, according to the AARI estimates. Monthly means of surface air temperature (Arctic Climatology Project 2000), snow depth and totals of the precipitation rate (Groisman et al. 1998) recorded by meteorological stations located in the study area are used to assess the influence of atmospheric conditions on fast ice. The $3 \mathrm{~h}$ time record of the wind strength and direction for Dikson Island is used to estimate the influence of wind stress on fast ice extent. Daily averages of sea level pressure on a $2.5^{\circ}$ latitude/longitude grid were derived from the $6 \mathrm{~h}$ data provided by the National Centers for Environmental Prediction, Camp Springs, MD. Monthly means of the flow rates of the $\mathrm{Ob}$ and Enisey rivers, acquired during 1950-1987, are used in the present study as well (Martin \& Munoz 1995). We also used the twice-

Variability and climate sensitivity of fast ice extent 

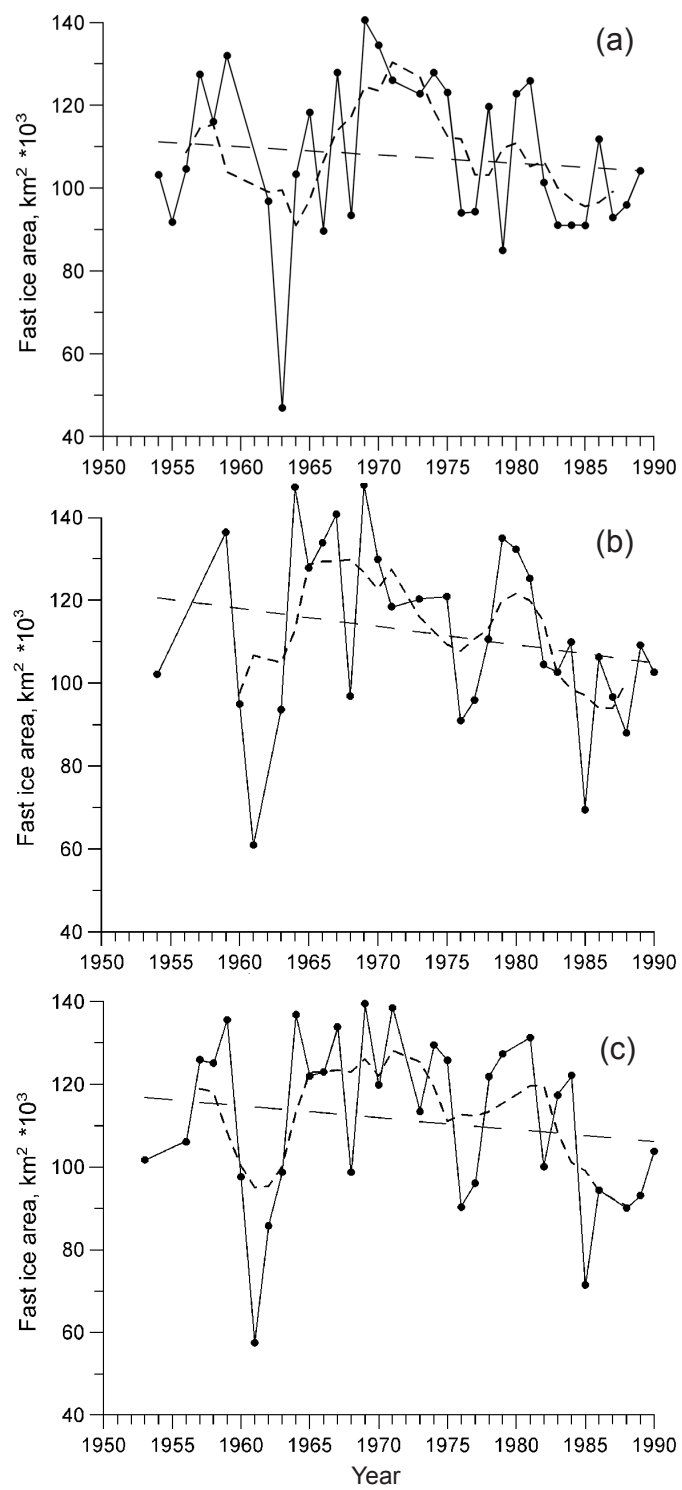

Fig. 2. Mean area of fast ice in the north-eastern part of the Kara Sea (a) in March, (b) April and (c) May during 1953-1990. The linear fits (long dashed lines) and 5-year running average (short dashed lines) are superimposed on each figure.

Table 1. Results of linear trend analysis for the area of fast ice in spring. The third column is a relative decrease of mean fas ice area in 1953-55 compared to 1988-1990.

\begin{tabular}{|c|c|c|}
\hline Month & $\begin{array}{l}\text { Trend magnitude } \\
\left(\mathrm{km}^{2 *} \text { year }^{-1}\right)\end{array}$ & $\begin{array}{l}\text { Relative decrease } \\
\text { of fast ice area (\%) }\end{array}$ \\
\hline March & -170 & 7 \\
\hline April & -440 & 12 \\
\hline May & -300 & 10 \\
\hline
\end{tabular}

Divine et al. 2003: Polar Research 22(1), 27-34 daily Northern Hemisphere extratropical cyclone data set (Serreze 1996) to analyse cyclone activity in the study area in the winters of 1979 and 1985.

\section{Results}

Analysis of AARI data shows that shore-fast ice extent in the north-eastern Kara Sea varies significantly from year to year. For example, in 1979 the area of fast ice in the north-eastern Kara Sea was as high as $125000 \mathrm{~km}^{2}$ and in April 1985 it was as low as $58000 \mathrm{~km}^{2}$. Figure $2 \mathrm{a}-\mathrm{c}$ show time series of fast ice area in March, April and May. Results of the linear regression analysis are imposed on each figure together with a 5-year running mean. All linear trends show decreases in the area of fast ice. The magnitudes of trends and relative decrease in the mean fast ice area in 1988-1990 compared to 1953-55 are presented in Table 1. The value of the relative decrease in April is close to the error interval in determination of fast ice area, which is about $6.5 \%$ according to the AARI estimates. More observations are required for March and May to assess the statistical significance of the trends.

A prominent feature of fast ice regime in the Kara Sea is a bimodality of fast ice area noted by Borodachev et al. (2000). Figure 3 shows histograms of fast ice area in the northeastern Kara Sea for spring months. Two modes, with areas of about $90000-110000 \mathrm{~km}^{2}$ and $120000-130000 \mathrm{~km}^{2}$, are distinguished. Together they cover about $55 \%$ of observations during 1953-1990.

Table 2 shows correlations between the average winter surface air temperature anomalies and the anomalies of fast ice area in May. We define the average winter air temperature for each cold season as an arithmetic mean of air temperature monthly means during September-April. Coefficients were calculated for 10 meteorological stations located in the study area. The air temperature anomalies at each station were normalized by division of each monthly mean temperature by the multi-year mean (1950-1990) standard deviation for the given month. All correlations are significant and close to -0.55 . April shows similar results.

To investigate the spatial variability of the average winter air temperature, correlations were calculated among all stations. The average winter temperatures are highly correlated over 
the whole region. The correlation coefficients lie in the range $0.8-0.9$. With correlation coefficients approaching 0.95-0.99, time series of mean monthly air temperatures correlate even more strongly than seasonal means. This shows that the temperature anomaly is stable across the entire north-eastern Kara Sea. We therefore conclude that the area of fast ice in April and May in this region correlates-with a value close to -0.55 - with winter temperature.

No significant correlations were found between fast ice extent and cumulative winter precipitation or with average winthertime snow depth. Analysis of the sensitivity of fast ice extent in AprilMay to the wind direction points to the significant role of eastward and north-eastward winds in fast ice development during the winter season (September-April). This relationship has a correlation coefficient of -0.5 . A weaker, but still significant, correlation of about 0.4 characterizes the sensitivity of fast ice extent to westward and north-westward wind transport during the cold season. This indicates that prevailing westward wind transport across the north-eastern Kara Sea creates favourable conditions for shore-fast ice expansion and the eastward wind tends to impede it. Wind data analysis also indicates that winds from the north-east during June-July increases fast ice destruction while winds from the northwest tend to restrain it. This tendency decreases for stronger winds from these directions. No correlations were found between fast ice extent and the preceding summer river outflow rate. Data analysis shows that discharge from the $\mathrm{Ob}$ and Enisey rivers is likely important in the outflow zone around $100 \mathrm{~km}$ of the rivers' mouths, since fast ice tends to break up first in these areas in the

Table 2. Correlation coefficient (r) of average surface air temperature anomalies in September-April for different locations in the north-eastern Kara Sea and average fast ice area anomalies in May. The stations are enumerated as in Fig. 1.

\begin{tabular}{ll}
\hline Station & $\mathrm{r}$ \\
\hline (1) Dikson Island & -0.57 \\
(2) Izvestiy ZIK Island & -0.60 \\
(3) Sterlegova Cape & -0.58 \\
(4) Isachenko Island & -0.51 \\
(5) Pravdy Island & -0.59 \\
(6) Russkiy Island & -0.56 \\
(7) Geyberga Island & -0.45 \\
(8) Krasnophlotskie Islands & -0.57 \\
(9) Golomyannyy Cape & -0.47 \\
(10) Uedineniya Island & -0.53 \\
\hline
\end{tabular}
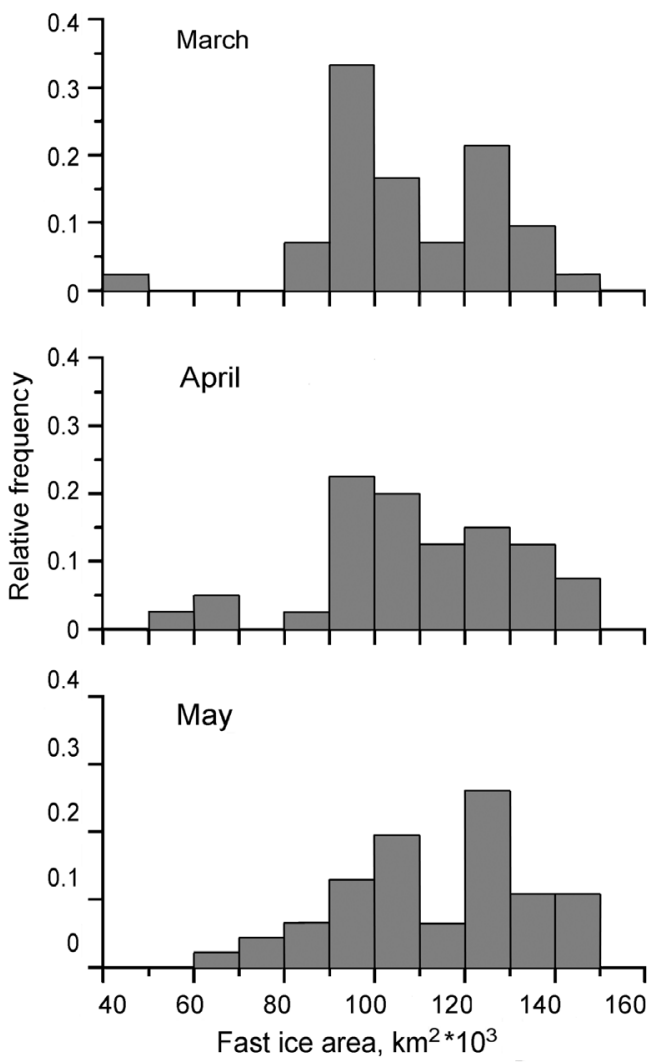

Fig. 3. Frequency distribution of shore-fast ice area in the north-eastern part of the Kara Sea in March, April and May 1953-1990.

beginning of June.

The years 1979 and 1985 are two examples of extreme formation of shore-fast ice in the northeastern Kara Sea. Figure 4 shows time series of fast ice area during the 1978/79 and 1984/85 cold seasons. Analysis of Fig. 4 and the surveys for these years reveal that formation of a stable belt of fast ice along the shore of the Taymyr Peninsula were completed in 1984/85 with a delay of about 40 days compared to $1978 / 79$. The most dramatic difference between the two scenarios is in March-April. Significant expansion of shore-fast ice occurred during the second half of March to the first 10 days of April 1979, whereas the development of fast ice in the same period of 1985 is characterized by a two-stage break-up. In the first stage, which occurred during the second and third 10-day periods in March, a partial break-up of fast ice occurred between Russkiy Island and the Severnaya Zemlya archipelago. In the second

Variability and climate sensitivity of fast ice extent 


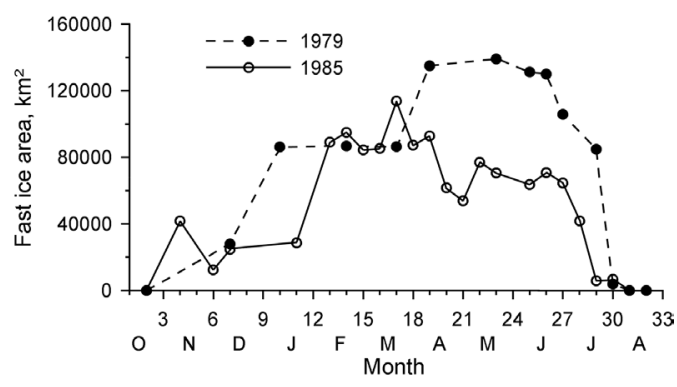

Fig. 4. Seasonal variability of fast ice area in the north-eastern Kara Sea in the 1978/79 and 1984/85 cold seasons. Note that the time axis is rearranged to coincide with the freeze season. The number on the time axis accounts for the 10-day period starting from the beginning of October.

stage most of the fast ice between Dikson and Isachenko islands broke up; this took place in the second 10-day period in April.

Detailed analysis of the meteorological conditions in the reference periods was carried out to reveal the source of these differences. The temperature regimes at three locations in the study area (Fig. 5) in the cold seasons of 1978/79 and the 1984/85 were rather different, elucidating the above-mentioned relationships between the anomalies of the surface air temperature and extent of shore-fast ice. The difference in mean monthly surface air temperature reaches $15^{\circ} \mathrm{C}$ in the winter months. It should also be noted that if mean monthly surface air temperatures in 1985 are close or slightly above the climate means, the temperature regime in 1979 exhibits negative temperature anomalies reaching $10^{\circ} \mathrm{C}$ below the average.

Wind regimes show different directions of wind transport as well (Fig. 6). During SeptemberMarch 1978/79 the prevailing surface wind direction at Dikson Island was between $80^{\circ}-160^{\circ}$, which corresponds to a north-westward geostrophic wind, taking into account the tuning angle of about $25^{\circ}$ (Overland \& Davidson 1992). The wind regime in 1985 did not exhibit as clear a picture as that of 1979 . The monthly mean wind direction changed between $100^{\circ}$ and $260^{\circ}$, with an average during September-March close to $220^{\circ}$ which means that a south-westerly wind prevailed this year. One can expect in this case onshore ice drift from the western Kara Sea compressing on fast ice in the north-eastern part of the sea. The mean monthly sea level pressure maps (not shown) confirm the surface wind data.

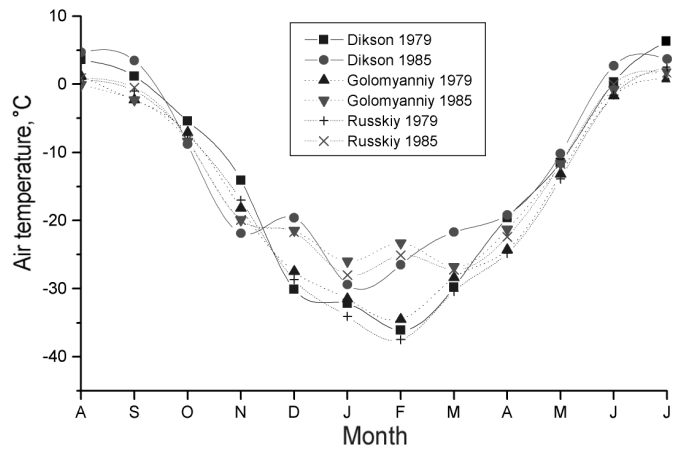

Fig. 5. Mean monthly air temperature at Dikson Island, Golomyannyy Cape and Russkiy Island in the 1978/79 and the 1984/85 winter seasons. The time axis is rearranged to coincide with the freeze season.

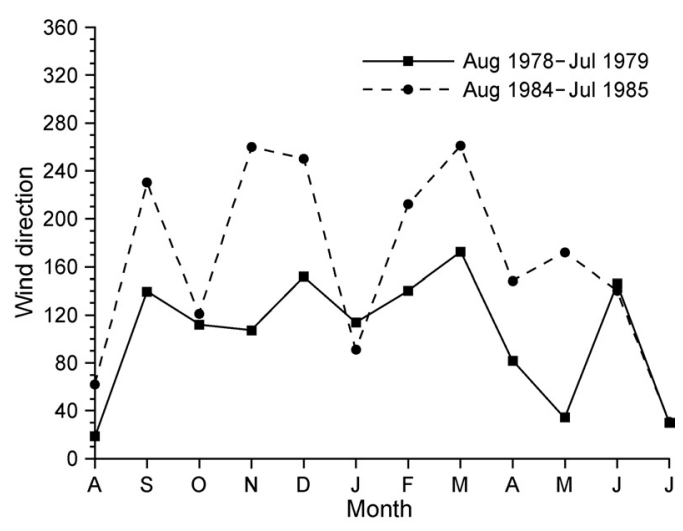

Fig. 6. Mean monthly values of wind direction at Dikson Island meteorological station during the 1978/79 and the $1984 / 85$ winter seasons. The time axis is rearranged to coincide with the freeze season.

A comparison of cyclone activity in the Kara Sea for these particular years has shown that it was nearly the same during September-February for both seasons. However, a rather significant distinction arose in March-April. While cyclone activity diminished in March-April 1979, in 1985 five cyclones traversed the study area. One can relate these facts to the observed events of shorefast growth and break-up.

The most likely candidates inducing the partial break-ups of shore-fast in March-April 1985 are cyclones which tracked the north-eastern Kara Sea during 12-16 and 22-27 March, and 16-20 April. Figure 7 shows sea level pressure fields averaged over the passage time and tracks of the cyclones. One can suggest that during the 

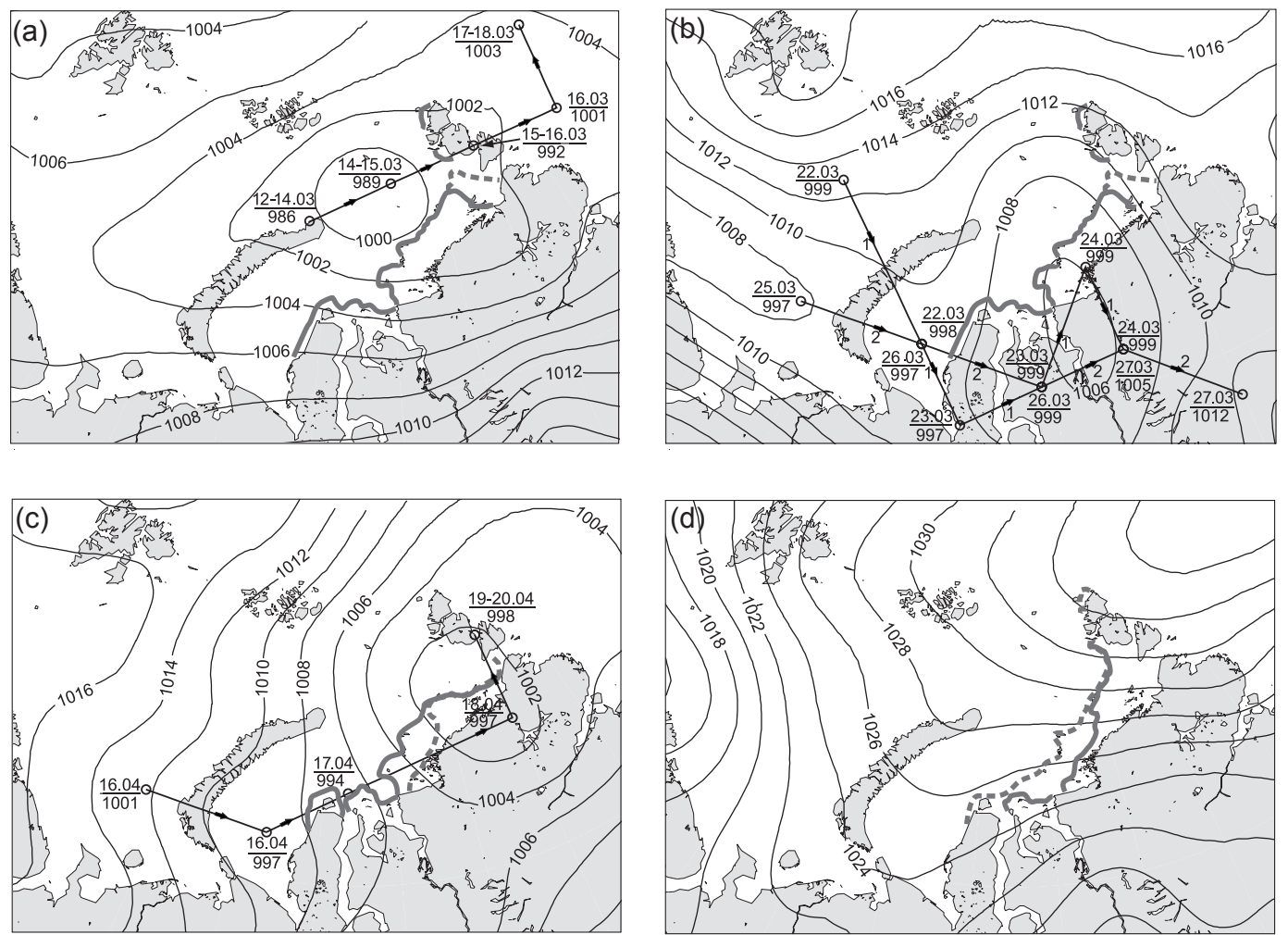

Fig. 7. Cyclone passage time-averaged sea level pressure in (a) 12-18 March, (b) 22-27 March and (c) 16-20 April of 1985. (d) Mean sea level pressure during 10 March to 10 April 1979. Straight lines show the track of the centre of the cyclonic system on the $47 \times 51$ octagonal grid. The date (DD.M) and cyclone central pressure (mb) is given in the subscription near the open circle designating the position of the system centre. Numbers 1 and 2 in (b) denote the first and second cyclones detected during the reference period. The thick grey solid and dashed lines denote the border of fast ice at the beginning and the end of the reference periods: 10-30 March 1985 (a, b), 10-30 April 1985 (c) and 10 March to 10 April 1979 (d). Note that these lines are merged on (a) and (b) along most of the fast ice border, highlighting the zone of the partial break-up near the Severnaya Zemlya archipelago.

first stage two principal mechanisms of fast ice break-up took place: a rise in sea level during the passage of the cyclone, induced by an inverted barometer effect, and the water drag stress. Proshutinsky et al. (2001) has shown that the variation in atmospheric pressure in winter accounts for the short-term sea level variability in the Kara Sea. Borodachev (1998) has pointed to the key role played by cyclone passage in inducing sea level rise during the partial break-up of shore fast in the south-western part of the Kara Sea. The location of the break-up zone near Severnaya Zemlya-just where the Western Taymyr Current encounters the steep coast of the archipelago (Fig. 1) and where significant current velocities (up to $100 \mathrm{~cm} / \mathrm{s}$ ) are observed (Volkov et al. 2002) - suggests that these strong currents could also have played an important role in the partial break-up of fast ice which occurred during $10-30$ March 1985.

The second stage of the partial break-up was initiated by sea level rise during the passage of the cyclone across fast ice (Fig. 7c). At the same time, the wind speeds registered at Dikson Island during these periods do not exceed $12 \mathrm{~m} / \mathrm{s}$, with average values of about $7.5 \mathrm{~m} / \mathrm{s}$ and $4 \mathrm{~m} / \mathrm{s}$ during the first and second stages, respectively (Fig. 8). This is close to or below the climate average for March and suggests that the role of the wind stress was diminished.

In contrast to 1985, March-April 1979 was characterized by a total absence of cyclone activity in the study area. The area of the Kara Sea was controlled by the high pressure system, located to the north-east of Severnaya Zemlya (Fig. 7d), which hinders the penetration of cyclones into the

Variability and climate sensitivity of fast ice extent 

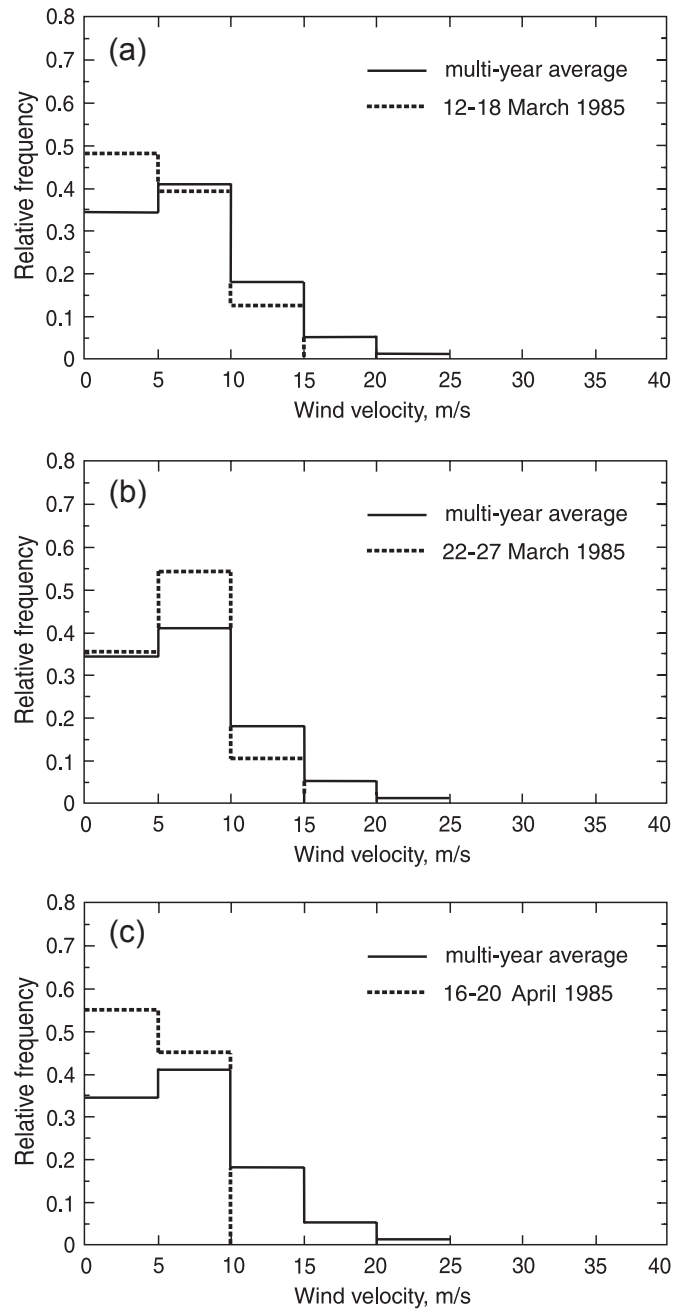

Fig. 8. Relative frequency distribution of wind velocities registered at Dikson Island during the passage time of cyclones during (a) 12-18 March, (b) 22-27 March and (c) 16-20 April 1985 (dashed lines) and the multi-year average for these months (solid lines).

Kara Sea and determines the north-westward offshore wind transport in the entire basin.

The thickness of fast ice registered at several locations in the north-eastern Kara Sea shows a significant positive anomaly during the whole winter of 1979 (Borodachev 1998; Volkov et al. 2002). At Isachenko Island, in particular, the ice thickness anomaly amouting to about $+35 \mathrm{~cm}-$ close to the absolute maximum-lasted through March-May 1979. In contrast to 1979, the spatial distribution of ice thickness in April 1985 is a negative anomaly - about $-50 \mathrm{~cm}$ - over the entire north-eastern Kara Sea (Romanov 1995). Simple estimates prove the weaker susceptibility of thicker fast ice to atmospheric forcing. An assessment of the impact of wind drag stress on fast ice shows that the critical wind velocity required for failure in 1985 is about 0.75 that for 1979. Given the ca. $170 \mathrm{~cm}$ ice thickness for the study area by the end of April, the stretch of fast ice of about $100 \mathrm{~km}$ and the surface drag coefficient at the upper limit of $5^{*} 10^{-3}$, the estimations with formulas given in Crocker \& Wadhams (1989) yield the values of the critical wind velocities for 1979 and 1985: about 30 and $23 \mathrm{~m} / \mathrm{s}$, respectively. If the first number is on the very edge, the second one falls well within the range of wind velocities observed in the study area (see example for March in Fig. 8). However, an assessment of the sensitivity of shore-fast ice to variation of sea level requires detailed study involving the modelling of the propagation of cycloneinduced surge over the area with complex topography.

We assume that conclusions drawn for these two particular years can be extended over time. However, the number of surveys, especially before the middle of the $1970 \mathrm{~s}$, is insufficient to capture the variability of shore-fast ice extent on a synoptic time scale. However, the existing data do catch the variability of shore-fast ice in the north-eastern Kara Sea on monthly and interannual time scales.

\section{Summary}

These results show that the extent of shore-fast ice in the north-eastern Kara Sea undergoes significant variability on both seasonal and interannual time scales. The frequency distribution of fast ice area in the north-eastern Kara Sea in spring is bimodal. Modes with larger $\left(120-130 * 10^{3} \mathrm{~km}^{2}\right)$ and smaller $\left(90-110 * 10^{3} \mathrm{~km}^{2}\right)$ areas are distinguished.

The linear trends for the time record of shorefast ice area in spring show a decrease during 1953-1990. The average areas in March, April and May in 1988-1990, estimated from time series of the AARI data, are approximately 7, 12 and $10 \%$ lower than in 1953-1955. We explain these negative trends by the prevalence, since 1980, the mode with decreased fast ice area.

Among the examined hydrometeorological parameters that are the potential sources of fast 
ice variability on the interannual time scale, the surface air temperature and wind direction exert the most influence. We found that the correlation between average winter temperature during October-April and fast ice extent in May is about -0.55 . A similar relationship characterizes the negative role of westerly wind in fast ice development. The easterlies, in contrast, promote fast ice expansion. These two parameters account for nearly the $50 \%$ of the variability of shore-fast ice in the study area.

Combined analysis of wind data and river discharge volume in summer did not yield evidence of any direct influence of river run-off on fast ice development following the cold season. The river discharge is likely important in estuaries, since fast ice starts to break up first in these areas.

The investigation of shore-fast variation in 1979 and 1985 revealed that cyclone activity during winter and spring might significantly influence its fast ice development by inducing partial break-ups. Unfortunately, the temporal resolution of the existing data is insufficient for the examination of this assumption over the whole time span covered by the present study. We speculate that the increased frequency of westerlies may serve as an index for the increased cyclone activity during winter and consequently the probability of partial break-ups. The increased frequency of winds from the east during winter, in contrast, may result in a decrease of the surface air temperature in the study area, stimulating the thickening of ice and the formation of new ice on the borders of fast ice.

The examination of other parameters that might be responsible for the rest of the variability of shore-fast ice, such as water heat content in the beginning of the cold season or ice thickness and their spatial distribution, is problematic until the relevant data become publicly available.

Acknowledgements.-The Norwegian Research Council supported this work (project no. 128087/730). The authors thank the two reviewers whose comments helped improve the manuscript, and S. Divina for preparing Figs. 1 and 7. We are also grateful to the ACSYS project for financially supporting the participation of D. Divine in the Workshop on Sea Ice Extent and the Global Climate System, Toulouse, 15-19 April 2002.

\section{References}

Arctic Climatology Project 2000: Environmental Working Group Arctic meteorology and climate atlas. F. Fetterer \& V. Radionov (eds). Boulder: National Snow and Ice Data Center. CD-ROM

Borodachev, V. E. 1998: L'dy Karskogo Morya. (Ice in the Kara Sea.) St. Petersburg: Gidrometeoizdat.

Borodachev, V. E., Gudkovich, Z. M., Klyachkin, S. V. \& Smolyanitsky, V. M. 2000: Fast ice conditions in the Kara Sea and possible reasons of interannual changes of fast ice area. In: Transport and fate of contaminants in the northern seas. AARI final report. Tromsø, Norway: Norwegian Polar Institute.

Crocker, G. B. \& Wadhams, P. 1989: Breakup of Antarctic fast ice. Cold Reg. Sci. Technol. 17, 61-76.

Dethleff, D., Loewe, P. \& Kleine, E. 1998: The Laptev Sea flaw lead-detailed investigation on ice formation and export during 1991/1992 winter season. Cold Reg. Sci. Technol. 27, 225-243.

Eicken, H., Viehoff, T., Martin, T., Kolatschek, J., Alexandrov, V. \& Reimnitz, E. 1995: Studies of clean and sediment-laden ice in the Laptev Sea. Rep. Polar Res. 176 , 62-70.

Fetterer, F. \& Troisi, V. 1997: AARI 10-day Arctic Ocean EASE-grid sea-ice observations. Boulder: National Snow and Ice Data Center. Digital media.

Groisman, P., Koknaeva, V., Belokrylova, T. \& Sanina, A. 1998: Former Soviet Union monthly precipitation archive, 1891-1993. Digital media. Boulder: National Snow and Ice Data Center.

Martin, S. \& Munoz, E. 1995: Russian rivers data set. Digital media. Boulder: National Snow and Ice Data Center.

Overland, J. E. \& Davidson, K. L. 1992: Geostrophic drag coefficients over sea ice. Tellus 44A, 54-66.

Proshutinksy, A., Pavlov, V. \& Bourke, R. H. 2001: Sea level rise in the Arctic Ocean. Geophys. Res. Lett. 28, 2237-2240.

Reimnitz, E., Kassens, H. \& Eicken, H. 1995: Sediment transport by Laptev Sea ice. Rep. Polar Res. 176, 71-77.

Reimnitz, E., Marincovich Jr., L, McCormick, M. \& Briggs, W. M. 1992: Suspension freezing of bottom sediment and biota in the Northwest Passage and implications for Arctic Ocean sedimentation. Can. J. Earth Sci. 29, 693-703.

Romanov, I. P. 1995: Atlas of ice and snow of the Arctic Basin and Siberian shelf seas. New York: Backbone Publishing.

Serreze, M. C. 1996: Arctic cyclone track data set (19661993). Boulder: National Snow and Ice Data Center. Digital media.

Timokhov, L. A. 1994: Regional characteristics of the Laptev and the East Siberian seas: climate, topography, ice phases, thermohaline regime, circulation. Rep. Polar Res. 144, 1531.

Volkov, V. A., Johannessen, O. M., Borodachev, V. E., Voinov, G. N., Pettersson, L. H., Bobylev, L. P. \& Kouraev, A. V. 2002: Polar seas oceanography. an integrated case study of the Kara Sea. London: Springer.

Zubov, N. N. 1945: L'dy Arktiki. (Arctic ice.) Moscow: Izd. Glavsevmorputi. (Translated in 1963 by US Naval Oceanographic Office, Springfield.)

Variability and climate sensitivity of fast ice extent 